\title{
Population Status and Diurnal Behaviour of the Red-Headed Vulture (Sarcogyps calvus) in Anbu Khaireni, Tanahu, Nepal
}

\author{
Anil Kumar Sah ${ }^{1}$, Chitra Bahadur Baniya ${ }^{2}$, Hem Sagar Baral ${ }^{3}$, \\ Ram Asheswar Mandal ${ }^{2} *$ \\ ${ }^{1}$ Department of Forest, Babarmahal Kathandu Nepal \\ ${ }^{2}$ Central Department of Botany, Kiritpur Kathmandu, Nepal \\ ${ }^{2 *}$ Central Department of Botany, Kiritpur Kathmandu, Nepal \\ ${ }^{3}$ Conservation Program ZSL, Kathmandu Nepal, ZSL, Kathandu Nepal
}

\begin{abstract}
This study was objectively carried out to estimate population of red-headed vulture; documentation of its diurnal behavior, issues related to declining its number. Anbu Khairini, Tanahu Nepal was selected as study site. Data were collected applying transects walk technique maintaining $150 \mathrm{~m}$ width on both sides of road during December, February and March. The binocular was used to observe the diurnal behavior of the vulture and camera was used to capture their photographs. Scan sampling method was applied to collect behavior data systematically during day time for twelve hours. Collected data were analyzed using descriptive analysis and non parametric Chi-square test. There were two adults and one sub-adult Sarcogyps calvus at Anbu Khaireni area. Red-headed vulture spends its time about 44.45, 42.86, 5.87, 3.21, 1.3, 1.1 and 1.15\% for resting, flying, eating, scratching, sunning, disturbing and fighting respectively. Generally, the red-headed vulture was found resting on the branch of Bombax cieba and Lagerstoemia parviflora. Chi-square test showed that the population of the red-headed vulture has been declining significantly. This decline may be due to lack of carcasses since it was banning the dumping animal skeleton and carcass at this site. This study will contribute to conserve redheaded vulture in Nepal.
\end{abstract}

Keywords: diurnal behavior, red-headed vulture, habitat, declining

\section{INTRODUCTION}

The red-headed vulture (Sarcogyps calvus) is known as the Asian King vulture and also named as Indian Black vulture or Pondicherry vulture though these are unrelated species which share the names as king vulture and black vulture [1]. Small disjunct populations of red-headed vulture are mainly found in the Indian Subcontinent [2]. The red headed vulture is classified as Critically Endangered (CR) species by the IUCN Red List and listed under Appendix II of Convention on International Trade in Endangered Species [3]. The population status of red-headed vulture in the world was estimated to be 2,500-9,999 adults in $2013[4,5]$. The patchiness of its distribution across Indian sub continent is apparently may indicate the catastrophic recent declines.

Nepal is the home for all nine species of vultures $[6,7,8]$. Out of nine species, white-rumped vulture (Gyps bengalensis), slender-billed vulture (Gyps tenuirostris), Himalayan griffon (Gyps himalayensis), red-headed vulture (Sarcogyps calvus), Egyptian vulture (Neophron percnopterus) and lammergier vulture (Gypaetus barbatus) are resident here whereas eurasian griffon (Gyps fulvus) and cinereous vulture (Aegypius monachus) are winter visitors [6, 9].

The vulture especially red-headed vulture has restricted habitat. The carcass availability is most important point, whether it is sufficient vulture community enjoy too. Any disturbance in carcass can affect seriously to the population. The red-headed vulture is very limited in number and its habitat is very limited in the world and in Nepal as well. These days, climate change, global warming and urbanization are the major problem of vulture. Anbu Khairani is small metropolitan in Tanahu district. The population of red-headed was good in Tanahu district but it has been declining days. However, the population status of the red-headed vulture has not been explored at Anbu Kharini region.

The context and temporal dynamics of red-headed vulture was not been assessed yet particularly surrounding of Anbu Khairini area of Tanahu. The birds have unique behavior. Their roosting, 
nesting, resting, eating, sleeping and daily movement is differed. Most of the literatures were related to other behavior of vulture but the assessment of behavior red-headed vulture has not assessed yet. The trend of temperature and rainfall are affecting the surrounding which may one of cause of threat the population of vulture. However, the variations in climatic parameters have not been explored of this location. Therefore, this study was objectively carried out to assess the population and behavior of red-headed vulture at Anbu Kharini, its diurnal behavior and causes of declining population.

\section{Materials ANd Methods}

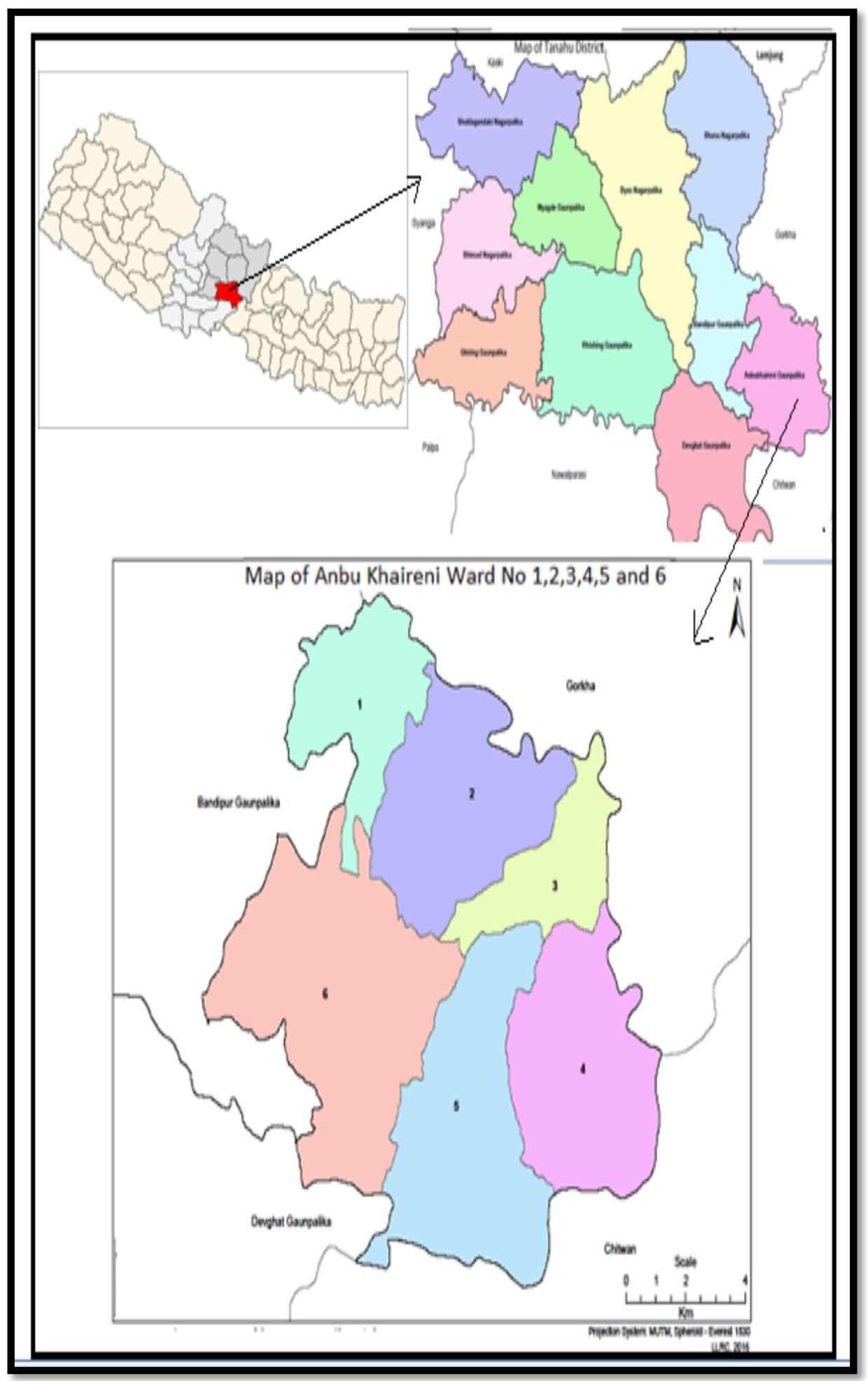

Figure 1. Map of Study Area

Study area: Study area lies in the Tanahu district of Nepal. Elevation of Tanahu District ranges between 300 to 2,000 meters. The latitude and longitude of Anbu Khaireni is $27^{\circ} 54^{\prime} 13.32^{\prime \prime} \mathrm{N}$, $84^{\circ} 32^{\prime} 23.64^{\prime \prime}$ E. Total Area of Anbu Khaireni is $67.3 \mathrm{~km} 2(26.0 \mathrm{sq} \mathrm{mi})$. Anbu Khaireni lies in 
northern part of ward no 5 of this municipality (Figure 1). Presently this is rural municipality. There were 376 households and 1453 population in this ward. Out of this, there were 715 male and 738 female [10]. The study area was the dumping site of two municipalities namely Anbu Khaireni and Muglin Bazar as well as different parts of Tanahu and Chitwan urban areas. The carcass from waste and decayed materials was sufficiently available as meal of vulture. But this was the seasonal and temporary habitat of the red headed vulture. The vulture was generally available between December to March but this depends up on the availability of carcass.

Data collection and analysis: Transect survey technique was applied to collect the primary data on each population. Transects were laid in such a way that these were cover all ecological habitats such as canals, wetlands, agricultural lands, reservoirs etc. according to participatory map. Therefore, before the transect survey the participatory location map had prepared with the help of local people. The transect survey was covered by using motorcycle and on foot. The speed of the motorcycle was maintained at $10 \mathrm{~km}$ per hour for survey purpose. Next, the bike was stopped at every $1 \mathrm{~km}$ interval for searching red-headed vulture. Meanwhile the transect width was maintained as about $150 \mathrm{~m}$ either sides. In addition, GPS receiver was used to record the X and Y coordinates of habitat of red-headed vulture. At the same time binoculars were used to observe the behavior patterns of the vulture and they were recorded by using the standard tally sheet and photographs taken with the help of camera. The purpose this record was enumeration of the different stages of vulture population. The records of population observations were classified into pairs or pairs with juveniles.

Scan sampling method was applied to collect behavior data systematically. Their behaviors were recorded categorically during the day time for twelve hours or more. These behaviors include resting positions, comfort movements (sunning and scratching), locomotion (flying), food intake and interindividual or social behavior (disturbance and fighting),

Social survey was carried out at three levels based on the type of information that would be generated at each level. These comprised of: Household survey carried out among 46 households out of 376 total households in Aambu Khareni, ward-5 in Tanahu. A total of 46 people found involved in implementation of vulture conservation initiatives, experts and researchers whom approached for questionnaire for this survey to get in-depth information on the research findings and their opinion on vulture conservation. Also, focus group discussion was conducted for the key informants during this study $[11,12]$.

Statistical analyses were performed by using Windows based statistical packages-Microsoft Excel, and $\mathrm{R}$ software package. The non-parametric test was used such as Chi-square test was applied for testing the association analyses between variables. For hypothesis testing $\mathrm{P}<0.05$ was considered and these levels of significance were indicated as appropriate. Although Chi-square results were presented in many tables and graphs figures, where the data were used in percentages, the analyses were done only on frequencies.

\section{RESUlts}

Population Status of red-headed vultures: Entire survey was carried out in four kilometer of the Anbu khaireni area, Tanahu of Nepal. Population count, nest count and habitat preference of vultures was studied at Anbu khaireni Area in Tanahu District. The total sampling effort of $4 \mathrm{~km}$ was invested in study area. This survey recorded one pair adult red-headed vultures with one sub-adult red-headed vulture (Table 1 and Figures 1 and Figure 2). The sightings in each of the studied site comprised of adult and sub-adult vultures.

Table 1. Number of vulture observed in study area

\begin{tabular}{|l|l|l|l|}
\hline Observed Vulture Species & \multicolumn{3}{|c|}{ Stage } \\
\hline Observation Date: 2016/12/25 to 2016/12/31 & Adult & Sub-Adult & Total \\
\hline Red-headed Vulture (Sarcogyps calvus) & 2 & 1 & 3 \\
\hline Observation Date: 2017/02/01 to 2017/02/06 & 0 & 0 & 0 \\
\hline Red-headed Vulture (Sarcogyps calvus) & 1 & 0 & 0 \\
\hline unknown vulture & \multicolumn{3}{|l|}{} \\
\hline Observation Date: 2017/03/01 to 2017/03/06 & 0 & 0 & 0 \\
\hline Red-headed Vulture (Sarcogyps calvus) & 0 & \\
\hline
\end{tabular}




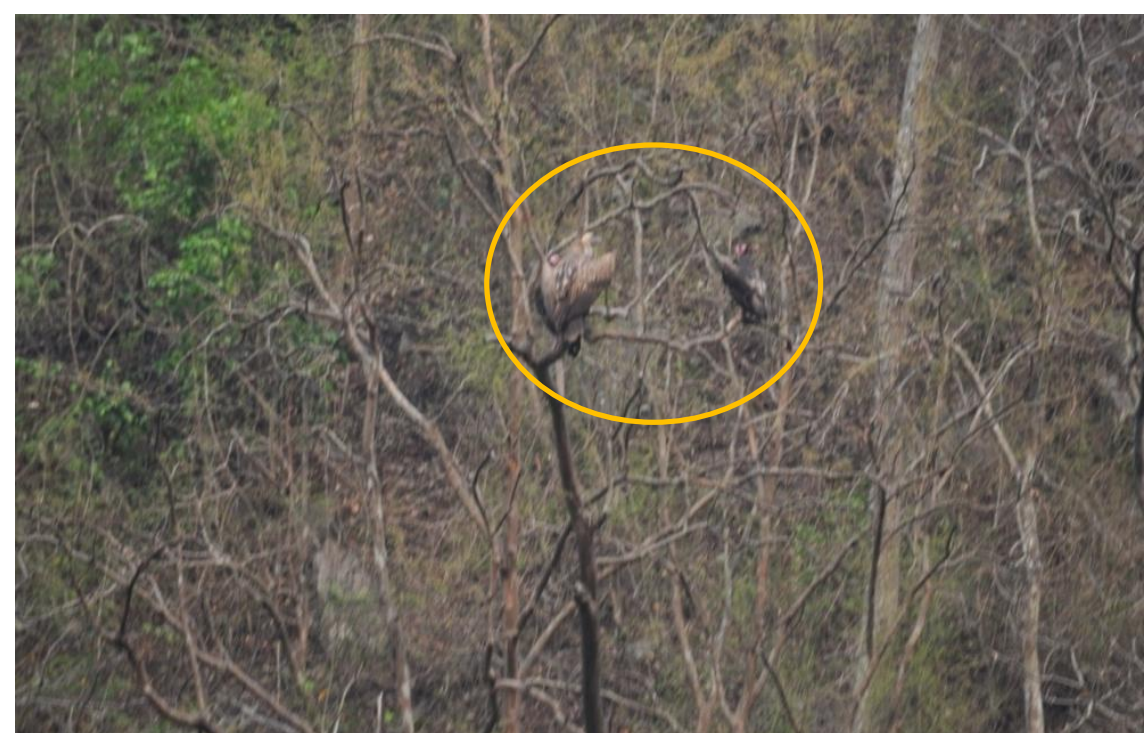

Figure 1. Captured Photos in Study site

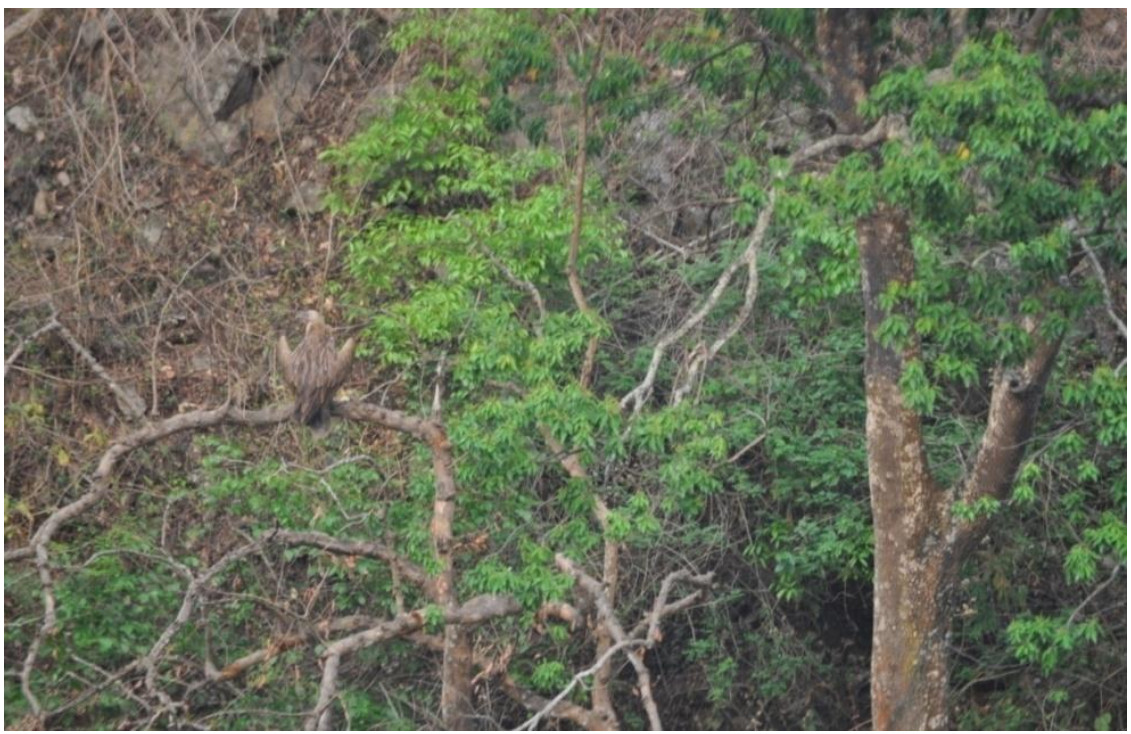

Figure 2. Captured Photos in Study site

The red-headed vultures were found resting mainly on two plant species namely Bombax ceiba and Lagerstroemia parviflora. However, red-headed vulture prefers to rest on the branch of Adina cordifolia, Sapium insigne, Terminalia bellirica, Shorea robusta, Premna integrifolia and Litsea polyantha etc.

\section{Behaviors of red headed vulture:}

Fashionable vulture and flying in style:: This particular bird has a few other names including the Asian King vulture, Indian Black vulture and in our country calling name is 'Soon Gidha' Golden vulture so this vultures are fashionable vulture. The red-headed vulture had a sense of style with their dark black feathers and bright red head. The adults tend to be a little flashier than the juveniles, which was the complete opposite with humans.

Sneaky vultures: Like other vultures, the red-headed vultures were typically feed on carrion and can often be found around the carcasses of large mammals. In these instances, they are often sharing the food with a variety of vulture species. Despite the gaudy appearance of the red-headed vulture they tended to be quite, timid when other vultures were feeding off of the same animal. This just goes to show that there was a hierarchy around every dinner table. Although they may be timid, the redheaded vulture can still be sneaky and has been known to steal food from their dinner mates. Perhaps the tameness was just a play so the other birds drop their guard.

Two is better Than One: When they weren't sharing a meal with other vultures, the red-headed vulture tended to spend their time alone or in a pair. They were rarely seen congregating in a group. 
When a male and female meet they will typically perform a variety of aerial acrobats to impress the other. Once this pair forms they will become a team and work together to defend their territory. I guess two was always better than one.

Diurnal Behaviors: Red-headed vulture showed different patterns of frequency of behavior in study site. Altogether 7 activities were recorded. Feeding, resting, sunning, scratching, fighting and fights were frequently observed behaviors in the studied sites (Figure $1 \& 2$ ). Resting behavior was most frequent $(44.45 \%)$ followed by fight (42.86\%), Feeding (5.87\%), Scratching (3.21\%), Sunning $(1.3 \%)$, Disturbance $(1.16 \%)$ and Fighting $(1.15 \%)$ were frequent behaviors in sites.

Local peoples' perception about Population Declining: Among 46 respondents asked in semistructure questionnaire survey among them $39.13 \%$ stated that the red headed vulture population has been declining for $<10$ years. This was followed by $34.78 \%$ of respondents saying population decliningwithin $1-5$ years; $21.74 \%$ of respondents saying population decline for 10 years; and $4.35 \%$ of respondents saying population decline for 5-10 years.

In addition, $65.22 \%$ respondents stated that the main cause of loss of population of red headed vulture was due to habitat loss and food scarcity but remaining $34.78 \%$ respondents answered only food scarcity was the main cause of declining.

The Chi-square test applied to compare the duration of declining population of red-headed of vulture as respondents' answer showed there was a significant difference in people perception about period of declining population of red-headed vulture (Table 2).

Table 2. Comparing the people's perception of time duration of population decline

\begin{tabular}{|l|l|l|l|l|l|}
\hline Declining period & $\begin{array}{l}\text { Observed frequency } \\
\text { (Oi ) }\end{array}$ & $\begin{array}{l}\text { Expected frequency } \\
\text { (Ei) }\end{array}$ & (Oi-Ei ) & (Oi-Ei)2 & (Oi-Ei)2/Ei \\
\hline 1 to 5 & 34.78 & 67.39 & -32.61 & 1063.33 & 15.78 \\
\hline 5 to 10 & 4.35 & 52.17 & -47.83 & 2287.33 & 43.84 \\
\hline 10 & 21.74 & 60.87 & -39.13 & 1531.19 & 25.16 \\
\hline$>10$ & 39.13 & 69.57 & -30.43 & 926.28 & 13.32 \\
\hline
\end{tabular}

Estimate Value of Chi-square test was 98.09, Tabulated value was 7.815.

The Chi-square test was applied to compare where the response of participants regarding on cause of declining population of red headed vulture significant or not. The Chi-square test showed that the estimated value was greater than tabulated value (Table 3 ). That means there was a significant difference in people perception about causes of declining population of red headed vulture.

Table 3. Comparing the people's perception of population decline

\begin{tabular}{|l|l|l|l|l|l|}
\hline Cause of declining & $\begin{array}{l}\text { Observed frequency } \\
(\mathrm{Oi})\end{array}$ & $\begin{array}{l}\text { Expected } \\
\text { frequency (Ei) }\end{array}$ & $(\mathrm{Oi}-\mathrm{Ei})$ & $(\mathrm{Oi}-\mathrm{Ei}) 2$ & $(\mathrm{Oi}-\mathrm{Ei}) 2 / \mathrm{Ei}$ \\
\hline Habitat loss \& food scarcity & 65.22 & 82.61 & -17.39 & 302.46 & 3.661327 \\
\hline Lack of food & 34.78 & 67.39 & -32.61 & 1063.33 & 15.7784 \\
\hline
\end{tabular}

Estimate Value of Chi-square test was 19.44, Tabulated value was 3.841

\section{DISCUSSION}

Suitable Climate of red-headed vulture: Pokhara valley is a laboratory without four walls for vulture research in Nepal. There are nine vulture species in our country [4], I have recorded six species here. Four species are confirmed to breed in the valley: white-rumped vulture (Gyps bengalensis), slender billed vulture (Gyps tenuirostris), Egyptian vulture (Neophron percnopterus) and red-headed vulture (Sarcogyps calvus). The valley has the sub-tropical climate. The absolute maximum and minimum temperatures were recorded $33^{\circ} \mathrm{C}$ in April and $5.6^{\circ} \mathrm{C}$ in January, respectively and the highest rainfall in Nepal occurs here [13]. The minimum and maximum temperatures of both sites were approximately similar.

Egyptian vultures were recorded in all five districts surveyed. Red-headed vultures were recorded in four districts except Salyan[14]. The Ghachowk vulture restaurant, established during 2010, is located in a river valley in the foothills of the Himalayas about $15 \mathrm{~km}$ northeast of Pokhara. Highland species 
are most common, including up to 50 Himalayan Griffons ( $G$. himalayensis), white-rumped and redheaded vultures, although a few slender billed and one Cinereous vulture (Aegypius monachus) were seen as well [15].

Globally the species have also been recorded from Bangladesh, Bhutan, Cambodia, China, India, Laos, Malaysia, Myanmar, Nepal, Pakistan, Thailand, Vietnam [2, 16]. Red-headed vulture was recorded for the first time in 19th century in Kathmandu Valley [17, 18]. Globally, vulture population is estimated to be 3,750-14,999 individuals, while 200-400 individuals are in Nepal $[19,16]$. In Nepal it has been recorded from the altitude of $75 \mathrm{~m}$ to $2000 \mathrm{~m}$ asl [16]. It is mostly found in open country near habitation, wooded hills, and dry deciduous forest with rivers [20].

Red-headed vultures were found to be distributed between $123 \mathrm{~m}$ to $1,550 \mathrm{~m}$ asl. Similar finding within the similar range of recording red-headed vulture in Kaski district at the altitude of 1,388m asl [21]. [22] Recorded red-headed vulture at lowland (Lalmatiya and Bijauri) of Dang Valley at the altitude of $150 \mathrm{~m}$ asl. [23] recorded red-headed in Tanahu within an altitude of 310 to $1120 \mathrm{~m}$ asl, which is quite similar with the present finding.

Eight vulture species in spring season and six vulture species in summer season were recorded in this study. [24] Recorded very close number of vulture species; seven vulture species in spring season and five vulture species in summer season in Rupandehi and Dang districts. Similarly, [25] recorded six vulture species in spring season in Tanahu district. [24] Also recorded five vulture species in summer season in Arghakhanchi, which showed similar findings and suggests that more species in spring and less in summer season. Similar with finding as [24] recorded griffon in spring in Rupendhei, [26] recorded Himalayan vulture and Bearded vultures in April (spring season) in recorded white-rumped, red-headed, Egyptian, Himalayan and Cinereous vultures in spring Season in Tanahu. These areas are the favorable climatic condition for red-headed vulture.

Population status distribution: This study has recorded three red-headed vulture species at Anbu Khairini. Out of this, two was adults and one was sub-adult. The total population of this vulture is less than 500 in Nepal. Three were found in study site, also the red-headed vulture is mostly found with white-rumped vulture. [5] calculate a decline in excess of 90\% within 10 years in India. Similar declines are expected throughout the Indian Subcontinent. The population of red-headed vulture is common in Nepal. It was more number of red-headed vultures in Anbu Khairinin but these days it is declining.

The study done by [14] regarding the vulture in middle mountain range of the western and midwestern development region of Nepal showed that the population of red-headed vulture was recorded two adults each in Arghakhanchi and Pyuthan districts. Meanwhile same report showed that, four and five adult red-headed vulture in Palpa and Kaski respectively. On the other hand two, one and three immature red-headed vultures were reported in Arghakhanchi, Palpa and Kaski districts respectively.

The study done by [27] and [19] showed that there was a temporal decreasing trend of the vulture population in Nepal. The red-headed vulture population was reported one each in 2002 and 2003 and two in 2009. [28] Described vultures are facing many survival problems in China. Poisoning, wind power stations, poaching, capture, specimen trade, highway construction and the use of vulture parts for cultural purposes are all threats. Due to development in the western regions of the country, vultures in China face a series of threats. The main threats in China are poisoning, specimen making and trading, food shortage, and demand by zoos, medicinal value and illegal hunting.

[29] had documented presence of "Globally threatened, NT and restricted-range bird species in twenty seven Important Bird Areas (IBAs) of Nepal with brief description of their status and threats. They mention the presences of white-rumped vulture in 19 IBAs but currently the presence is limited to16 Important Bird Areas (IBAs). SBV was reported from16 IBAs but the presence is now limited to 13 IBAs. The authors identified hunting, trapping, and use of pesticides, poisoning and loss of prey as the major cause in decline of white-rumped vulture, slender billed vulture, cinereous vulture and redheaded vulture.

Sarcogyps calvus has suffered an extremely rapid population reduction in the recent past which is likely to continue into the near future, probably largely as a result of feeding on carcasses of animals treated with the veterinary drug diclofenac, perhaps in combination with other causes. For this reason it is classified as Critically Endangered. Historical reports indicate that it was widespread and 
generally abundant, but it has undergone a population and range decline in recent decades. Recent information indicates that in India the King vulture started undergoing a rapid decline (41\% per year) in about 1999, and declined by $91 \%$ between the early 1990s and 2003 [5]. Declines in the Indian subcontinent have followed widely reported and well-researched declines in Gyps vultures owing to mortality ingestion of the non-steroidal anti-inflammatory drug (NSAID) diclofenac, used to treat livestock, and it is hypothesized that this same drug has been responsible for the observed trends in red-headed vulture. The manufactures and importation of veterinary diclofenac was banned in India in May 2006 with bans in Nepal and Pakistan in the same year. Although the large number of manufacturers and availability of meloxicam is encouraging, the wide range of untested NSAIDs and continued availability of diclafenac is major source of concern. But the 2006 diclofenac ban is being followed by illegally selling forms of diclofenac manufactured for human use for veterinary purposes.

Sarcogyps Calvus visits from Nepal, Bangladesh, Thailand, China and Burma. Sevens pecies have been recorded at Jorbeer [30] i.e. long billed vulture (Gyps indicus), white backed vulture (Gyps bengalensis), Eurasian griffon vulture (Gyps fulvus), Himalayan griffon vultures (Gyps himalayensis), King vulture (Sarcogyps calvus), Cinereous vulture (Ageypius monachus) and Egyptian vulture (Neophron percnopterus) as nine species of vultures found in Indian subcontinent [4].

The disappearance of vultures from Asia is linked to a suite of factors: notably the demise of wild ungulates [31], the intensification of agriculture, increased sophistication of waste disposal techniques, direct persecution and disease. However, rapid declines since the turn of 21 st Century are believed to have been driven by the pharmaceutical NSAID diclofenac used to treat livestock, which has proven highly toxic to vultures, causing mortality from renal failure that results in visral gout [5].

Dead feral and domestic cows are left in the open in rural areas or disposed of in carcass dumps around towns and cities [32].

Behaviors of red-headed Vulture: The high livestock availability went in favor of vulture food security due to possible availability of carcasses and carrion. However, the situation on the ground was different since, most of the cattle were sold before they grew old. Moreover it was found that forested districts had larger number of vultures since they provided both domestic as well as wild animals for food. According to [33], Uttar Pradesh, India is an agriculture dominated state, with a livestock population of 64 million where disposal of dead animals was mainly done by removing carcasses to village outskirts, where dogs (Canis lupus familiarias), crows and egrets compete with vultures.

The dumping site at Anbu Khairini has been negatively imparting the effect to local people and living beings. So, the local people raised their voice to restrict the dump the waste material at this particular area. There is large conflict between local people and authority of urban area especially of Muglin market. These days, local people are too much aware about the problem of dumping site. They strictly banned to dump the materials here.

Spectacular daily activities of King Vultures (Sarcogyps Calvus) comprise feeding, scratching, sunning, resting, reaction to disturbance, flight and fight. It spends maximum time in resting and flight. The daily activities were observed from 7.00 hours in the morning up to 18.00 hours till evening Feeding comprises $2.87 \%$ of the total day activities. It was seen feeding alone like a King. It feeds between 10.00 hours to 1.00 hours and feeding continues up to 19 minutes in intervals. It was seen sitting lonely at the edge of dumping stand. There were very few interactions observed with other vultures during feeding. It spends maximum time in resting. Resting comprises $51.45 \%$ of the total day activity. It generally rest alone over the trees. Maximum resting was observed during morning. King vulture also rests in the evening between 15.00 hours to 18.00 hours. Sunning comprises $0.30 \%$ of the total day activities. It continues for 1-2 minutes. Sunning has done to warm the body parts. It spreads wings and keep its back towards sun. It comprises $0.21 \%$ of the total day activities. Scratching was done by beak probably to remove the pests. It was seen to get disturbed by dog bark, sound of vehicles and human approach to feeding site. Disturbance comprises of $0.16 \%$ of the total day actities. It reacts to disturbance by flying away from the site. King vulture rarely fights, few interactions were observed. Such an interaction comprises $0.15 \%$ of the total day activities. During feeding it dominates other vultures. It was never seen fighting with other vultures. King vulture was always observed sitting at isolated place. It comprises $45.15 \%$ of the total day activities Maximum flight was observed 
from 12.00 hours to 16.00 hours flights were also seen intermittently in morning hours. King vulture is an active vulture compare to other vultures species. It takes small flights and observed playing with small birds i.e. crows, eagles etc. during fly King vultures changes its place frequently [34].

Causes of declining population: The red-headed vulture has gone through a severe decline in numbers since the 1990s. The blame fell on the ingestion of carrion meat containing diclofenac, a non-steroidal anti-inflammatory drug (NSAID) meant as an anti-biotic for livestock; the drug causes kidney and renal failure in vultures and is fatal to the birds. In this studied site dead cattle were usually left at the place where they have died, where they are eaten by the vultures. In the area, foraging sites for red-headed were found diminishing and also becoming more distant, which was an alarming threat to the red-headed population.

The roosting area at Anbu Khaireni was with heavy traffic incurring excessive air and noise pollution. Although the report of hunting was very occasional but local people throw stones to fly away redheaded vulture if found in trees in their land due to negative attitude.

The people observed the red-headed vulture resting on the big plants in the forest, canals and cultivated land but they have not seen in urban areas. Luckily, I observed the vulture resting on large plant in the forest and canals area.

\section{CONCLUSION AND RECOMMENDATION}

There were two adults and one sub adult vulture at Anbu Khairini. The daily activities were observed from 7.00 hours in the morning up to 18.00 hours till evening. Feeding comprises $2.87 \%$ of the total day activities. It was seen feeding alone like a King. It feeds between 10.00 hours to 1.00 hours and feeding continues up to 19 minutes intervals. The daily activities were observed from 7.00 hours in the morning up to 18.00 hours till evening Feeding comprises $2.87 \%$ of the total day activities. It was seen feeding alone like a King. It feeds between 10.00 hours to 1.00 hours and feeding continues up to 19 minutes in intervals. The availability of carcass is the major problem. The municipality also banned to dump the waste materials at Anbu Khairini.

Research is also urgently required to determine the principle threat or cumulative threats causing the declines of red-headed vultures. Diclofenac may be the principle cause, as with other Accipitridae vultures, however at this time it is not conclusively known. If further research is not conducted on these species and effective management plans are not put in place, I fear that red-headed vultures in particular, and indeed a number of other Accipitridae vultures may well be faced with extinction in the very near future.

\section{REFERENCES}

[1] Scopoli.; http://www.birdlife.org on 02/07/2016, (1786)

[2] BirdLife International "Sarcogyps calvus". IUCN Red List of Threatened Species. Version 2013.2. International Union for Conservation of Nature. Retrieved 26 November 2013.

[3] Convention on International Trade in Endangered Species of Wild Fauna and Flora (CITES) Appendices I, II and III valid from 1 July 2008, Geneva, Switzerland downloaded from http:// www.cites.org on 12 July 2008.

[4] Bird Conservation Nepal (BCN), Lazimpath, Kathmandu, Nepal. Annual Report 2013/14, (2014).

[5] Cuthbert, R., Green, R.E., Ranade, S., Saravanan, S., Pain, D.J., Prakash, V. and Cunningham, A.A. Rapid population declines of egyptian vulture (Neophron percnopterus) and red-headed vulture (Sarcogyps calvus) in India. Animal Conservation, 9: 349 - 354, (2006).

[6] DNPWC/MoFSC/GoN, Vulture Conservation Action Plan for Nepal. Government of Nepal, Ministry of Forest and Soil conservation, Department of National Park and Wildlife Conservation, Babarmahal, Kathmandu, Nepal, (2009).

[7] BCN and DNPWC. The State of Nepal's Birds 2010. Bird Conservation Nepal and Department of National Parks and Wildlife Conservation Nepal, Lazimpath and Kathmandu, Nepal, (2011).

[8] DNPWC, Vulture Conservation Action Plan for Nepal (2015-2019). Department of National Parks and Wildlife Conservation, Ministry of Forests and Soil conservation, Government of Nepal, Kathmandu, (2015). 
Population Status and Diurnal Behaviour of the Red-Headed Vulture (Sarcogyps calvus) in Anbu Khaireni, Tanahu, Nepal

[9] Harris, R.J.,The conservation of Accipitridae vultures of Nepal: a review. Journal of Threatened Taxa 5(2): 3603-3619; doi:10.11609/JoTT.o2816.3603-19, (2013).

[10] Central Bureau of Statistics (CBS), Government of Nepal, Kathmandu, Environment Statistics of Nepal, (2011).

[11] Gupta, S., Research Methodology and statistical techniques, Deep and Deep Publication PVT. LTD. F-159, Rajouri Garden, New Delhi-110 027. ISBN 81-7100-501-2, (2005).

[12] 12.EU-MIDIS ,Technical Report Methodology, Sampling and Fieldwork European Union Agency for Fundamental Rights, European Union Minorities and Discrimination Survey (English version) (2009).

[13] Baral N. and R. Gautam, Socio-economic perspectives on the conservation of critically endangered vultures in south-east Asia: an empirical study from Nepal. Bird Conservation International 17: 1-10(2007).

[14] Subedi, T.R. and DeCandido R. ,Population and breeding success of Red-headed Vulture Sarcogyps calvus and Egyptian Vulture Neophron percnopterus in Central West Nepal. Vulture News, 67: 21-32(2014).

[15] Nepal Jatayu, the vulture restaurants of Nepal, Robert Decandido, Tulsi Subedi \& Deborah Allen (2012).

[16] Inskipp C., Baral H.S., Phuyal S., Bhatt T.R., Khatiwada M., Inskipp, T. et al. 2016. The status of Nepal's Birds: The national red list series, Zoological Society of London, UK.

[17] Ali S and Ripley SD, Handbook of the Birds of India and Pakistan, Compact edition (Oxford University Press) Bombay (1983).

[18] Hodgson, B.H., Notes and original watercolor paintings of the birds of Nepal, Tibet and India, held in the Zoological Society of London Library, (Unpublished) 1829.

[19] Hodgson, B.H., Catalogue of Nepalese birds, collected between 1824 and 1844. In Gray, J. E., Zoological Miscellany, (June 1844).

[20] BirdLife International, Sarcogyps calvus. The IUCN Red List of Threatened Species2016:e.T22695254A93499732. http://dx.doi.org/10.2305/IUCN.UK.20163.RLTS.T22695254A93499732.en. Downloaded on 09 April 2017(2016).

[21] Grimmett, R., Inskipp, C. and Inskipp, T., A guide to the Birds of Nepal. Second edition, Christopher Helm, London, UK (2000).

[22] Gautam, R. \& Baral, N., Population Status and Breeding Success of Three Endangered Vulture Species in the Pokhara Valley, Kaski, Nepal. Final report submitted to The Peregrine Fund (USA) and Royal Society for the Protection of Birds (UK)( 2009).

[23] Shrestha, B.P. and Devkota, B.P., Status of Critically Endangered Vultures in Dang Deukhuri Foothill Forests and West Rapti Wetlands (2010).

[24] Gurung, R., Feeding Behavior of Vultures in Dumping Sites of Damauli, Tanahaun District, Nepal. M.Sc. Thesis, Central Department of Zoology, Tribhuvan University, Kathmandu, Nepal (2013).

[25] Dhakal, H., Sustainability of Vulture Safe Feeding Sites for the conservation of vultures in Rupendehi and Dang, Nepal. M.Sc. Thesis, Central Department of Zoology, Tribhuvan University, Kathmandu, Nepal(2012).

[26] Gurung, U. ,Breeding Success of White Rumped Vulture (Gyps bengalensis, Gmlin) around Vulture Restaurants in Pithauli and Kawasoti, Nawalparashi. M. Sc. Thesis. Central Department of Zoology, Tribhuvan University, Kathmandu, Nepal(2012).

[27] Karmacharya, D.K., Population status, breeding success and conservation approaches of vultures with special reference to Himalayan Griffon (Gyps himalayensis, Hume, 1969) in Khodpe, Baitadi, Nepal, M.Sc. Thesis. Central Department of Zoology, Tribhuvan University, Kathmandu, Nepal(2011).

[28] Chaudhary, A., CEPF Final Project Completion Report: Securing Safe Environment for Critically Endangered Vulture Species by Declaring and Ensuring Diclofenac Free Zones in Central and Western Low Lands of Nepal. Bird Conservation Nepal, Lazimpath, Kathmandu, Nepal. (Available in: http://www.cepf.net, Download date: April 24, 2013) (2011). 
[29] Maming, R. and Xu, G., Status and threats to vultures in China, The Journal of the IUCN Vulture Specialist Group Vulture News 68, pp 11-20 (2015).

[30] Baral,. H.S., and Inskipp, C., Important Bird Areas in Nepal: Key Sites for Conservation. Bird Conservation Nepal and BirdLife International, Kathmandu and Cambridge, ISBN 99933-792-20(2005).

[31] Khatri P.C., Status of Migratory Vultures at Jorbeer, Bikaner (Rajasthan). Life Sciences Leaflets 1 6-13(2013a).

[32] Anon., Red-headed Vulture breeding programme launched, Vulture News: 79-80(2007).

[33] Prakash, V. Pain, D.J. Cunningham, A.A. Donald, P.F. Praksah, N. Verma, A. Gargi, R. Sivakumar, S. Rahmani, A.R., Catastrophic collapse of Indian white-backed Gyps bengalensis and Long-billed Gyps indicus vulture populations. Biological Conservation, 109:381-390(2003).

[34] Jha, K. K., Distribution of vultures in Uttar Pradesh, India. Journal of Threatened Taxa, 7(1): 6750-6763(2015).

[35] Khatri P.C., The king is disappearing: a study of socio-ecological aspects of king vulture or redheaded vultures (sarcogyps calvus) at jorbeer, Bikaner, (2015). 